\title{
Integration of two-dimensional complex functions
}

\section{Lessow, H.; Schjær-Jacobsen, Hans}

\section{Published in:}

I E E E Transactions on Antennas and Propagation

Publication date:

1976

Document Version

Publisher's PDF, also known as Version of record

Link back to DTU Orbit

Citation (APA):

Lessow, H., \& Schjær-Jacobsen, H. (1976). Integration of two-dimensional complex functions. I E E E Transactions on Antennas and Propagation, 24(6), 908-909.

\section{General rights}

Copyright and moral rights for the publications made accessible in the public portal are retained by the authors and/or other copyright owners and it is a condition of accessing publications that users recognise and abide by the legal requirements associated with these rights.

- Users may download and print one copy of any publication from the public portal for the purpose of private study or research.

- You may not further distribute the material or use it for any profit-making activity or commercial gain

- You may freely distribute the URL identifying the publication in the public portal

If you believe that this document breaches copyright please contact us providing details, and we will remove access to the work immediately and investigate your claim. 
a horizontal antenna can be removed if it is situated at least $(0.7 / \sqrt{|\varepsilon|}) \lambda$ away from the ground plane. For the worst case $\phi(\nless x, r)=0$, it has been found that the reflection-coefficient method yields a solution within 10 percent of the exact Sommerfeld formulation both in the real and imaginary parts of impedance elements even when two horizontal currents are as mcuch as $1000 \lambda$ apart. All of the above restrictions are valid even for low values of the dielectric constant of the ground plane $(|\varepsilon| \approx 2)$. However, for parallel vertical wires over an imperfect ground plane the reflection coefficient method yields a result accurate to within 10 percent of the exact Sommerfeld formulation in both the real and imaginary parts of the impedance elements under all conditions of the ground as long as they are $(0.7)$ $\sqrt{|\varepsilon|} \lambda \lambda$ away from the surface of the ground plane.

Input data required for this program include the conductivity and the dielectric constant of the ground, the operating frequency, the total number of elements in the linear array, the radii and feed voltages of the wires, the lengths and spacings of individual elements, and the angular steps at which the specified field pattern is to be computed.

Computer output consists of all input data together with the current distribution of each wire, input impedances corresponding to feed points, and the normalized $E$-field pattern above earth with the appropriate normalization constant.

Storage required for execution of the analysis program which has been written in Fortran IV is $45.8 \mathrm{k}$-bytes. Time required by an IBM 370/150 computer for analyzing a linear array consisting of two half-wave wires using 7 expansion functions over each wire was 1.92 and $19.36 \mathrm{~s}$ for compilation and execution, respectively.

\section{ACKNOWLEDGMENT}

Thanks are due to Dr. Bradley J. Strait for valuable guidance and advice, and to Dr. R. F. Harrington for helpful suggestions.

\section{REFERENCES}

[1] R. F. Harrington, Field Computation by Moment Methods. New York: Macmillan, 1968.

[2] J. H. Richmond, "Mutual impedance between coplanar-skew dipoles," IEEE Trans. Antennas and Propagation, vol. AP-18, no. 3, pp. 414-416, May 1970.

[3] T. K. Sarkar, "An optimization program for linear arrays of parallel wires," IEEE Trans. Antennas and Propagation, vol. AP-22, no. 4, pp. 631-632, July 1974 .

[4] -Analysis of radiation by linear arrays of parallel vertical wire antennas over imperfect ground," IEEE Trans. Antennas and Propagat., vol. AP-23, no. 5 , Sept. 1975 .

[5] T. K. Sarkar and B. J. Strait, "Analysis of radiation by linear arrays of parallel horizontal wire antennas over imperfect ground," Scientific Report No. 5 on Contract F19628-73-C-0047, AFCRL-TR-74-0538, Syracuse University, Syracuse, NY.

[6] E. K. Miller, A. J. Poggio, G. J. Burke, and E. S. Selden, "Analysis of wire antennas in the presence of a conducting half space, Part II. The horizontal antenna in free space," Canadian Journal of Physics, vol. 50, pp. 2614-2627, 1972.

[7] T. K. Sarkar and B. J. Strait, "Analysis of radiation and optimization methods for arbitrary oriented antenna arrays over a plane imperfect ground," Scientific Report No. 9 on Contract F19628-73-C-0047, AFCRL-TR-75-0641, Syracuse University, Syracuse, NY, Oct. 1975.

\section{Integration of Two-Dimensional Complex Functions}

\section{NAMES:}

PURPOSE:

\section{LANGUAGE: AUTHORS:}

\section{AVAILABILITY: DESCRIPTION:}

\section{Fortran IV.}

H. A. Lessow and H. Schjær-Jacobsen, Electromagnetics Institute, Technical University of Denmark, Lyngby, Denmark.

\section{ASIS-NAPS Document NAPS 02786.}

The package consists of four integration programs each requiring approximately $3.2 \mathrm{~K}$ bytes on an IBM $370 / 165$.

Consider the integral $J$ of a complex valued function $F$ of two real variables $(x, y)$

$$
J=\int_{y_{l}}^{y_{u}} \int_{x_{l}}^{x_{u}} F(x, y) d x d y
$$

taken over the rectangular domain

$$
x_{l} \leq x \leq x_{u}, \quad y_{l} \leq y \leq y_{u} .
$$

An approximation to $J$ may be obtained by recursive application of a one-dimensional rule:

$$
J=\int_{y_{l}}^{y_{u}} f(y) d y
$$

where

$$
f(y)=\int_{x_{l}}^{x_{u}} F(x, y) d x
$$

where $J$ and $f(y)$ are the outer and inner integral, respectively,

Two one-dimensional rules have been implemented for evaluation of (3) and (4), namely the Simpson and Romberg methods [1]. Both make use of the trapezoidal approximation $T_{r}{ }^{(0)}$ to the integral calculated by means of a recurrence algorithm [2]. The Romberg extrapolated approximations to the integral are given by

$$
T_{r}^{(m)}=\frac{4^{m} T_{r}^{(m-1)}-T_{r-1}^{(m-1)}}{4^{m}-1}, \quad m=1,2, \cdots, r
$$

and the successive values of $T$ are stored in the $T$-table shown in Table I. The Simpson method falls out as the special case $m=1$ corresponding to the second column in Table I.

Fig. 1(a) shows the hierarchal structure of the computer programs applying the two methods. QATR2 (Romberg) or SIMP2 (Simpson) calculates the outer integral and QATR1 or SIMP1 the inner integral. MAIN and FCT are user-supplied programs of which FCT evaluates the complex function $F(x, y)$.

The Romberg integration process on the inner and outer integral is stopped whenever

\begin{tabular}{|c|c|c|c|c|c|c|}
\hline \multirow{2}{*}{$\begin{array}{l}r \\
0 \\
1 \\
2 \\
3 \\
4 \\
5\end{array}$} & $\begin{array}{c}\text { Number of } \\
\text { Integrand } \\
\text { Samples } \\
2^{r}+1\end{array}$ & \multicolumn{5}{|c|}{$\begin{array}{c}\text { Trapezoidal and Extrapolated } \\
\text { Approximations }\end{array}$} \\
\hline & $\begin{array}{r}2 \\
3 \\
5 \\
9 \\
17 \\
33\end{array}$ & $\begin{array}{l}T_{0}{ }^{(0)} \\
T_{1}{ }^{(0)} \\
T_{2}{ }^{(0)} \\
T_{3}{ }^{(0)}\end{array}$ & $\begin{array}{l}T_{1}(1) \\
T_{2}(1) \\
T_{3}(1)\end{array}$ & $\begin{array}{c}T_{2}^{(2)} \\
T_{3}^{(2)} \\
\vdots\end{array}$ & $T_{3}^{(3)}$ & $\because$ \\
\hline
\end{tabular}

$$
\left|\frac{T_{r}^{(m)}-T_{r-1}^{(m-1)}}{T_{r-1}^{(m-1)}}\right|<\varepsilon, \quad \text { for } m=r, r>2
$$

TABLE I

COMPIEX ROMBerg T-TABLE IN ONE-DIMENSIONAL INTEgRAL
Manuscript received June 21,1975

See NAPS document 02786 for 27 pages of supplementary material. Order from ASIS/NAPS c/o Microfiche Publications, 440 Park Avenue South, New York, NY 10016. Remit in advance for each NAPS accession number. Make checks payable to Microfiche Publications. Photocopies are $\$ 6.75$. Microfiche are $\$ 3.00$. Outside of the United States and Canada, postage is $\$ 2.00$ for a photocopy or $\$ 1.00$ for a fiche.

Authorized licensed use limited to: Danmarks Tekniske Informationscenter. Downloaded on October 9, 2009 at 08:05 from IEEE Xplore. Restrictions apply. 


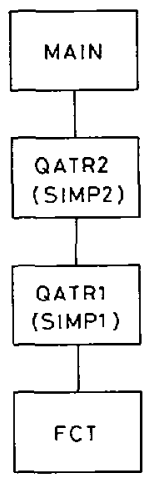

(a)

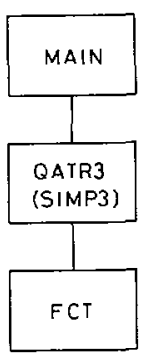

(b)
Fig. 1. Hierarchal structure of complex two-dimensional integration programs. (a) Romberg (Simpson) integration of inner and outer integration consecutively. (b) Romberg (Simpson) integration by two-dimensional algorithm.

where $\varepsilon$ is a user specified small positive number. The corresponding stop criterion in the Simpson integration is

$$
\left|\frac{T_{r}^{(1)}-T_{r-1}^{(1)}}{T_{r-1}^{(1)}}\right|<\varepsilon, \quad r>2 .
$$

The programs QATR3 and SIMP3 make use of a twodimensional trapezoidal algorithm [3] to approximate (1) directly:

$$
\begin{gathered}
T_{r}^{(0)}=\frac{1}{4} T_{r-1}^{(0)}+\frac{\Delta x \Delta y}{2^{2 r}}\left[\frac{1}{2} \sum_{j} F_{j}^{b o}+\sum_{k} F_{k}^{i n}\right] \\
T_{0}^{(0)}=\Delta x \Delta y \frac{1}{4} \sum_{i=1}^{4} F_{i}^{c o} \\
\Delta x=x_{u}-x_{l}, \Delta y=y_{u}-y_{l}
\end{gathered}
$$

where the $i$-summation includes the integrand sample points in the four corners of the rectangular integration interval. It is understood from (8) that the $r$ th trapezoidal approximation $T_{r}^{(0)}$ to the integrand is defined by $T_{r-1}^{(0)}$ and two summations over new sample points not involved in the calculation of $T_{r-1}^{(0)}$. The new sample points are homogeneously distributed over the integration interval by halving the mesh size (see Fig. 2). In (8) the superscript $b o$ indicates new sample points at the boundary of the integration interval whereas superscript in indicates interior points. Subsequently (5) is used for the Romberg extrapolations (QATR3) and with $m=1$ for the Simpson method (SIMP3). The convergence criteria used are as defined in (6) and (7). The program structure is shown in Fig. 1(b).

The program listings contain extensive information on input and output parameters. An example is shown in Fig. 3 for QATR2.

The programs described above have been used for the calculation of two-dimensional phase integrals and numerical results are given in [4].

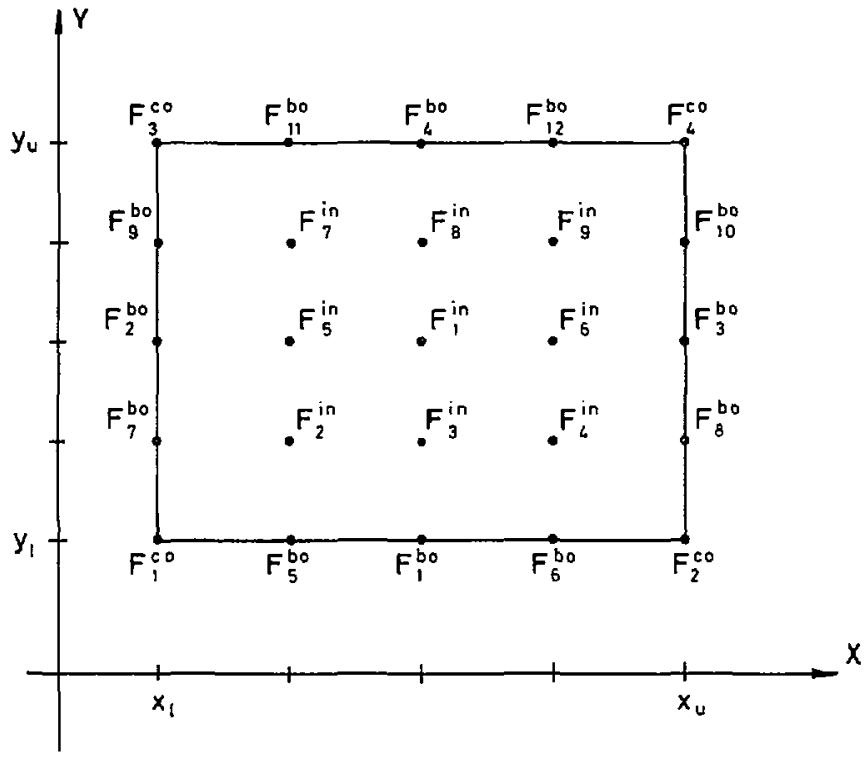

Fig. 2. Two-dimensional trapezoidal rule, $r=2$.

PURPOSE

TO COMPUTE AN APPROXIMATION FOR INTEGRAL OF COMPLEX FUNCTION FCT $(X 1, X 2)$, SUMMED OVER X1 AND X2 FROM XL1 TO XU1 USAGE

CALL QATR2 (XLI, XU1, XL2, XU2, EPS, NDIM,FCT, Y, IER, AU1, AU2)

PARAMETER FCT REQUIRES AN EXTERNAL STATEMENT.

DESCRIPTION OF PARAMETERS

XL1,XL2- THE LOWER BOUNDS OF THE INTERVALS.

XU1, XU2- THE UPPER BOUNDS OF THE INTERVALS.

EPS - THE UPPER BOUND OF THE RELATIVE ERROR.

NDIM - THE DIMENSION OF THE AUXILIARY STORAGE ARRAYS. ADIM-1 IS THE MAXIMAL NUMABER OF BISECTIONS OF THE INTERVALS (XL1,XU1) AND (XL2,XU2).

FCT - THE NAME OF THE EXTERNAL FUNCTION SUBPROGRAM USED.

$Y$ - THE RESULTING APPROXIMATION FOR THE INTEGRAL VALUE, IER - A RESULTING ERROR PARAMETER.

AU1, AU2- AUXILIARY STORAGE ARRAYS WITH DIMENSIONS NDIM.

REMARKS

ERROR PARAMETER IER IS CODED IN THE FOLLOWING FORM

IER $=0$ - IT WAS POSSIBLE TO REACH THE REQUIRED ACCURACY. NO ERROR.

IER $=2$ - IT WAS IMPOSSIBLE TO CHECK ACCURACY BECAUSE NDIM IS LESS THAN 3, OR THE REQUIREO ACCURACY COULD NOT BE REACHED WITHIN NDIM-1 STEPS. NDIM (OR EPS) SHOULD BE INCREASED.

Fig. 3. Input and output parameters for integration program QATR2.

\section{REFERENCES}

[1] P. J. Davis and P. Rabinowitz, Numerical Integration. Waltham, Mass.: Blaisdell Publishing Company, 1967.

[2] IBM System/360 Scientific Subroutine Package, Version III, Fifth Edition, p. 297, 1970.

[3] H. Schjær-Jacobsen, "Computer programs for one- and two-dimensional Romberg integration of complex functions," Report D 187, September 1973, Electromagnetics Institute, The Technical University of Denmark, Lyngby, Denmark.

[4] H. A. Lessow, W. V. T. Rusch, and H. Schjær-Jacobsen, "On numerical evaluation of two-dimensional phase integrals," IEEE Trans. Antennas and Propagation, vol. AP-23, no. 5, pp. 714-717, Sept. 1975. 